\title{
Cumulative concentrations of blood lead and postural stability
}

\author{
S E Chia, H P Chia, C N Ong, J Jeyaratnam
}

\begin{abstract}
Objective-To study the association in a group of battery manufacturing workers between computerised postural sway parameters and present concentrations of blood lead (PPb), index of cumulative blood lead years (CBI), and cumulative blood lead at different years of exposure (CPbYs).
\end{abstract}

Methods-Postural stability was investigated with a computerised postural sway measurement system in 60 workers exposed to lead with exposure duration of 84 (range 3-366) months and in 60 control subjects. An index of CBIs in 55 workers (previous blood lead results of five workers were not available) and CPbYs were computed for each worker by calculating the area under the curve of concentrations of blood lead against time.

Results-The mean (SD) PPb was 36.0 (11.7) (range 6.4 to 64.5$) \mu g / d l$ for the exposed workers and $6.3 \quad(2.4)$ (range $3 \cdot 1-10 \cdot 9) \mu \mathrm{g} / \mathrm{dl}$ for the 14 randomly selected control subjects. Significant differences between groups for the postural sway parameters obtained when the eyes were closed were found for length of sway path (L); mean velocity of the centre of pressure along its path (Vel); area included within the path of the centre of pressure $\left(A_{0}\right) ; 95 \%$ confidence elliptical area $\left(A_{e}\right)$. The Romberg ratio (the relation between eyes closed and open) for the Vel, $L, A_{o}$, and $A_{e}$ of the exposed group were also significantly different from those of the controls. The postural sway parameters (eyes closed) were not significantly correlated with $\mathrm{PPb}$ or CBI. However, the cumulative blood lead for the past two years before the postural sway assessment, CPbY2, was significantly correlated with all the postural sway parameters.

Conclusion-The study showed that workers exposed to lead had significantly poorer postural stability than a control group. Lead may affect certain parts of the somatosensory system resulting in postural instability when the visual input is cut off. The CPbY2 was significantly positively correlated with most of the postural sway parameters. Effects of lead on postural stability may be related to recent increases in blood lead concentration among the exposed workers rather than to cumulative body burden.
(Occup Environ Med 1996;53:264-268)

Keywords: postural stability; cumulative blood lead index

Postural sway abnormalities have been reported in children with lead intoxication. ${ }^{12}$ In adults, there was a case report of possible effects of lead on postural stability by Linz et $a l .^{3}$ They reported improvement in postural sway test performance after $\mathrm{Ca}^{++}$EDTA chelation in an adult worker with persistent central nervous system symptoms two years after an episode of subacute lead intoxication.

Recently, we reported that a group of lead battery workers had significantly poorer postural stability than non-exposed workers. ${ }^{4}$ In that study, we were unable to establish a significant relation between present concentrations of blood lead $(\mathrm{PPb})$ and postural sway parameters. This is expected as $\mathrm{PPb}$ of the exposed workers were a reflection of present not past exposure. In this present study we examined the association between the computerised postural sway parameters and $\mathrm{PPb}$, cumulative blood lead at different years of exposure ( $\mathrm{CPbYs}$ ), and an index of total cumulative blood lead years (CBI) for each worker exposed to lead.

\section{Material and methods}

STUDY POPULATION AND DESIGN

The details of the study population and design have been described in an earlier paper. ${ }^{4}$

The study was carried out at a lead storage battery factory involving 60 workers exposed to lead. None of these workers were chelated before. Sixty subjects, consisting of departmental staff and students, who are clinically healthy and with no exposure to neurotoxic agents served as the control group. Significant differences were noted in the age, height, and blood lead concentrations between the exposed and control groups (table 1). These factors were statistically adjusted in the subsequent analysis. All subjects were found to be clinically normal before they had the postural stability test.

\section{Computerised postural sway assessment}

Each subject was given two sets of tests. The first set consisted of three tests (each lasting 20 s) conducted with eyes open. The second set consisted of three tests (also $20 \mathrm{~s}$ each) conducted with eyes closed. 
Software supplied by AMTI, BEDAS-2 computer automated stability analysis, was used to compute the parameters relating to the changes in the centre of pressure from data taken while the subject was standing on the platform.

The sway parameters used for detecting changes in performance were: length of sway path (L); mean velocity of the centre of pressure along its path ( $\mathrm{Vel})$; area included within the path of the centre of pressure $\left(A_{0}\right)$; and 95\% confidence elliptical area $\left(A_{e}\right)$.

\section{BIOLOGICAL MEASUREMENTS}

All the exposed subjects and a sample of the controls $(n=14)$ had venous blood collected on the day the postural sway tests were conducted for measurement of whole blood lead concentrations. We did not subject all the controls to a blood test as the history did not suggest any lead exposure. Thus the interviewer randomly approached 14 control subjects to ask if they would volunteer their blood samples. All 14 control subjects agreed. The blood sample was obtained by venepuncture with lead free disposable syringes and was stored in lead free bottles. Blood lead (BPb) was measured with an atomic absorption spectrophotometer with a graphite furnace. External quality control was carried out under the national external quality assessment scheme (NEQAS) in the United Kingdom. The mean coefficients of variation between NEQAS values and our results has been less than $5 \%$ for the last 10 years.

Concentrations of $\mathrm{BPb}$ had been measured every six months since 1979 for this factory. Past records of $\mathrm{BPb}$ were available for 55 out of 60 exposed workers. As an index of the body burden of lead, the cumulative concentrations of $\mathrm{BPb}$ for each worker ( $\mathrm{CPbYe}$ ) was computed by calculating the area under the curve of $\mathrm{BPb}$ for each year of exposure to lead from the date of the test (postural stability) with the formula:

CPbYe $=0.5 \Sigma\left(t_{e+1}-t_{e}\right)\left(B P b_{e}+B P b_{e+1}\right)$

where $t_{e}=$ time interval (in years) from the date of the test and $\mathrm{BPb}_{\mathrm{e}}=$ blood lead value at the corresponding year (fig 1). Also, CBIthat is, the total blood lead accumulated over the period of working in the factory-was computed for each worker by the same formula with $t_{c}=$ total years of exposure to lead in the factory. Among the longer serving exposed workers, there were no pre-employment $\mathrm{BPb}$ measurements nor regular periodic examinations in the early years. For these

Table 1 Characteristics of the study population

\begin{tabular}{|c|c|c|c|}
\hline & $\begin{array}{l}\text { Exposed } \\
\text { mean }(S D) \\
(n=60)\end{array}$ & $\begin{array}{l}\text { Control } \\
\text { mean }(S D) \\
(n=60)\end{array}$ & $P$ values \\
\hline $\begin{array}{l}\text { Age (y) } \\
\text { Height (cm) } \\
\text { Weight }(\mathrm{kg}) \\
\text { Subjects who drank }(\%)^{\star} \\
\text { Exposure (months) } \\
\text { Blood lead ( } \mu \mathrm{g} / \mathrm{dl})\end{array}$ & $\begin{array}{c}31 \cdot 6(7 \cdot 7) \\
166 \cdot 3(8 \cdot 1) \\
65 \cdot 2(11 \cdot 7) \\
5 \cdot 0 \\
84 \cdot 0(86 \cdot 7) \\
36 \cdot 0(11 \cdot 7)\end{array}$ & $\begin{array}{l}35 \cdot 4(7 \cdot 4) \\
169 \cdot 3(6 \cdot 2) \\
64 \cdot 9(7 \cdot 6) \\
11 \cdot 7 \\
-6 \cdot 3(2 \cdot 4) \dagger\end{array}$ & $\begin{array}{l}0.0071 \\
0.0256 \\
\text { NS } \\
\text { NS } \\
-0.0001\end{array}$ \\
\hline
\end{tabular}

*All of the subjects who drank were occasional and social drinkers, they drank less than once month, each time no more than two large bottles of beer; fresults for 14 control subjects.

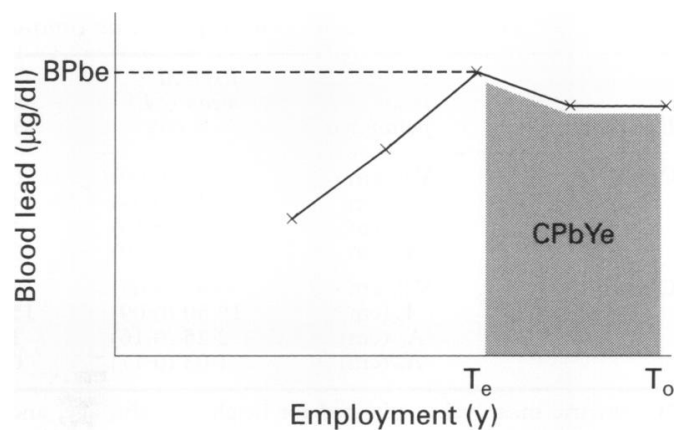

Figure 1 Computation of cumulative BPb for each worker (CPbYe) by years before postural stability test $T_{o}=$ date of postural stability test; $T_{e}=$ time interval $(y)$ from $T_{o} ; B P b e=$ blood lead value at the corresponding year.

workers (10 out of 55), the first available $\mathrm{BPb}$ reading was linearly extrapolated backwards to a pre-employment value of $6.3 \mu \mathrm{g} / \mathrm{dl}$. The concentration of $6.3 \mu \mathrm{g} / \mathrm{dl}$ was chosen because this was the mean $\mathrm{BPb}$ value of the control group.

\section{STATISTICS}

Logarithmic transformation was applied to all the sway parameter data to improve normality. Data for $\mathrm{BPb}$ were not log transformed as they were normally distributed. None of the correlation coefficients between the various postural sway parameters and weight, age, and height were more than 0.5 . As such, the problem of collinearity was minimised. Differences between the exposed and control subjects' postural sway parameters were tested by analysis of covariance (ANCOVA) with adjustment for age, height, weight, and drinking habits. Education was not taken into consideration as it has never been reported to affect postural stability. ${ }^{5-7}$ The statistical analysis was run on the IBM 3081 mainframe computer with the Statistical Analysis System (SAS) package. The PROC CORR and PROC GLM procedures were used.

\section{Results}

Table 2 shows the adjusted mean postural sway parameters of the exposed and control groups. There were significant differences between them for Vel, $L, A_{0}$, and $A_{e}$ when the eyes were closed. No significant differences were noted between the exposed and control groups for the sway parameters obtained with eyes open (table 2). The controls' Romberg ratios for Vel, $L, A_{0}$, and $A_{e}$ were near unity (table 3). There was at least a $20 \%$ difference between the values for closed and open eyes of the postural sway parameters $\left(\mathrm{Vel}, \mathrm{L}, \mathrm{A}_{0}\right.$, and $A_{e}$ ) of the exposed group.

Table 4 shows the Pearson's correlation coefficients $(r)$ between some postural sway parameters (significantly different from the controls) and the different indices of cumulative blood lead. The cumulative blood lead calculated one year before the date of testing is $\mathrm{CPbY} 1$. Likewise, CPbY2 to CPbY10 are the values calculated for two to 10 years from the date of postural sway assessment. The postural sway parameters were not significantly correlated with $\mathrm{PPb}$ or $\mathrm{CBI}$. The $\mathrm{CPbY} 2$ was 
Table 2 Postural sway parameters for exposed and control groups

\begin{tabular}{|c|c|c|c|c|}
\hline Eyes condition & $\begin{array}{l}\text { Postural } \\
\text { sway } \\
\text { parameters }\end{array}$ & $\begin{array}{l}\text { Exposed } \\
\text { mean }(S E) \\
(n=60)\end{array}$ & $\begin{array}{l}\text { Control } \\
\text { mean }(S E) \\
(n=60)\end{array}$ & $P$ values \\
\hline Open & $\begin{array}{c}\text { Vel }\left(\mathrm{cm} \mathrm{s}^{-1}\right) \\
\mathrm{L}(\mathrm{cm}) \\
\mathrm{A}_{\mathrm{o}}(\mathrm{cm}) \\
\mathrm{A}_{\mathrm{e}}(\mathrm{cm})\end{array}$ & $\begin{array}{r}0.77(0.09) \\
15.40(0.09) \\
1.67(0.16) \\
0.84(0.19)\end{array}$ & $\begin{array}{r}0.74(0.09) \\
14.70(0.09) \\
1.51(0.17) \\
0.76(0.19)\end{array}$ & $\begin{array}{l}\text { NS } \\
\text { NS } \\
\text { NS } \\
\text { NS }\end{array}$ \\
\hline Closed & $\begin{array}{c}\text { Vel }\left(\mathrm{cm} \mathrm{s}^{-1}\right) \\
\mathrm{L}(\mathrm{cm}) \\
\mathrm{A}_{\mathrm{o}}(\mathrm{cm}) \\
\mathrm{A}_{\mathrm{e}}(\mathrm{cm})\end{array}$ & $\begin{array}{r}0.93(0.09) \\
18.50(0.09) \\
2.25(0.16) \\
1.03(0.17)\end{array}$ & $\begin{array}{r}0.77(0.09) \\
15.40(0.09) \\
1.55(0.16) \\
0.74(0.17)\end{array}$ & $\begin{array}{l}0.0014 \\
0.0014 \\
0.0002 \\
0.0018\end{array}$ \\
\hline
\end{tabular}

${ }^{\star}$ Geometric mean value adjusted for height, weight, age, and drinking habits. SE = standard error on a $\log$ scale.

Table 3 Romberg ratios (RRs) for some postural sway parameters between the exposed and control populations

\begin{tabular}{llll}
\hline $\begin{array}{l}\text { Postural sway } \\
\text { parameters }\end{array}$ & $\begin{array}{l}\text { Exposed } R R^{*} \\
(n=60)\end{array}$ & $\begin{array}{l}\text { Control } R R^{*} \\
(n=60)\end{array}$ & P values \\
\hline Vel & 1.20 & 1.04 & 0.0206 \\
$\mathrm{~L}$ & 1.20 & 1.04 & 0.0207 \\
$\mathrm{~A}_{\mathrm{o}}$ & 1.34 & 1.02 & 0.0100 \\
$\mathrm{~A}_{\mathrm{e}}$ & 1.23 & 0.98 & 0.0311 \\
\hline
\end{tabular}

* Romberg ratio $(R R)=$ ratio of the postural sway parameters measured with eyes closed and eyes open.

significantly correlated with all the postural sway parameters. Also, CPbY9 was significantly correlated with the postural sway parameters $A_{o}$, and $A_{e}$. Table 5 was tabulated to examine if the significant association found earlier between $\mathrm{CPbY} 2$ and most of the postural sway parameters could have been contributed by workers with longer exposure. Table 5 shows the $r$ values between the postural sway parameters and the different CBIs for workers excluding the 22 workers with more than six years of exposure who have contributed to CPbY9 (table 4). The $r$ values for $\mathrm{CPbY} 2$ with the postural parameters were, in fact, stronger showing that the observed association was not affected by the group of workers with longer exposure (table 5).

Table 4 Pearson's correlation coefficients between various postural sway parameters and different indices of cumulative blood lead concentration by years for all workers

\begin{tabular}{|c|c|c|c|c|c|}
\hline & & Exposed & sway parar & s closed) & \\
\hline & & Vel & $L$ & $A_{o}$ & $A e$ \\
\hline $\begin{array}{l}\text { PPb } \\
\text { CBI } \\
\text { CPbY1 } \\
\text { CPbY2 } \\
\text { CPbY3 } \\
\text { CPbY4 } \\
\text { CPbY5 } \\
\text { CPbY6 } \\
\text { CPbY7 } \\
\text { CPbY8 } \\
\text { CPbY9 } \\
\text { CPbY10 }\end{array}$ & $\begin{array}{l}(n=60) \\
(n=55) \\
(n=55) \\
(n=45) \\
(n=41) \\
(n=36) \\
(n=31) \\
(n=27) \\
(n=25) \\
(n=23) \\
(n=22) \\
(n=19)\end{array}$ & $\begin{array}{l}0.129 \\
0.071 \\
0.066 \\
0.343^{\star} \\
0.111 \\
0.121 \\
0.207 \\
0.073 \\
-0.019 \\
-0.121 \\
0.271 \\
0.132\end{array}$ & $\begin{array}{l}0.129 \\
0.070 \\
0.066 \\
0.343^{\star} \\
0.111 \\
0.121 \\
0.206 \\
0.072 \\
-0.020 \\
-0.121 \\
0.270 \\
0.131\end{array}$ & $\begin{array}{l}0 \cdot 238 \\
0.094 \\
0 \cdot 127 \\
0.405^{\star \star} \\
0 \cdot 110 \\
0.182 \\
0 \cdot 232 \\
0.193 \\
0 \cdot 156 \\
0.094 \\
0.431^{\star} \\
0.304\end{array}$ & $\begin{array}{l}0.233 \\
0.110 \\
0 \cdot 122 \\
0.367^{\star} \\
0.080 \\
0.204 \\
0.233 \\
0.239 \\
0 \cdot 241 \\
0 \cdot 222 \\
0.443^{\star} \\
0.369\end{array}$ \\
\hline
\end{tabular}

$\star P<0.05 ;{ }^{\star \star} P<0.01$

Table 5 Pearson's correlation coefficients between various postural sway parameters and different indices of cumulative blood lead concentration by years for all workers with $\leqslant 6$ years of exposures

\begin{tabular}{|c|c|c|c|c|c|}
\hline & & \multicolumn{4}{|c|}{ Exposed postural sway parameter (eyes closed) } \\
\hline & & Vel & $L$ & $A_{o}$ & $A_{e}$ \\
\hline $\begin{array}{l}\text { PPb } \\
\text { CBI } \\
\text { CPbY1 } \\
\text { CPbY2 } \\
\text { CPbY3 } \\
\text { CPbY4 } \\
\text { CPbY5 } \\
\text { CPbY6 }\end{array}$ & $\begin{array}{l}(n=38) \\
(n=33) \\
(n=33) \\
(n=23) \\
(n=19) \\
(n=14) \\
(n=9) \\
(n=5)\end{array}$ & $\begin{array}{l}0.129 \\
0.162 \\
0.131 \\
0.630^{\star \star} \\
0.431 \\
0.480 \\
0.663 \\
0.559\end{array}$ & $\begin{array}{l}0.198 \\
0.162 \\
0.131 \\
0.630^{\star \star} \\
0.431 \\
0.480 \\
0.664 \\
0.559\end{array}$ & $\begin{array}{l}0.285 \\
0.204 \\
0.162 \\
0.599^{\star \star} \\
0.189 \\
0.406 \\
0.506 \\
0.541\end{array}$ & $\begin{array}{c}0.257 \\
0.169 \\
0.122 \\
0.485^{\star} \\
-0.046 \\
0.251 \\
0.276 \\
0.388\end{array}$ \\
\hline
\end{tabular}

$\star P<0.05 ;{ }^{\star} \star P<0.01$.

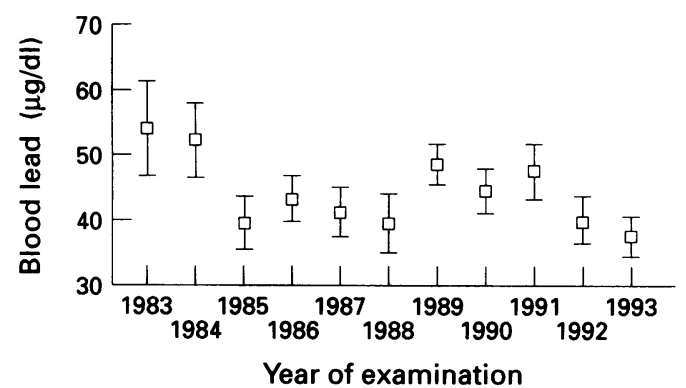

Figure 2 Mean (95\% CI) concentration of blood lead for workers with more than six years of exposure.

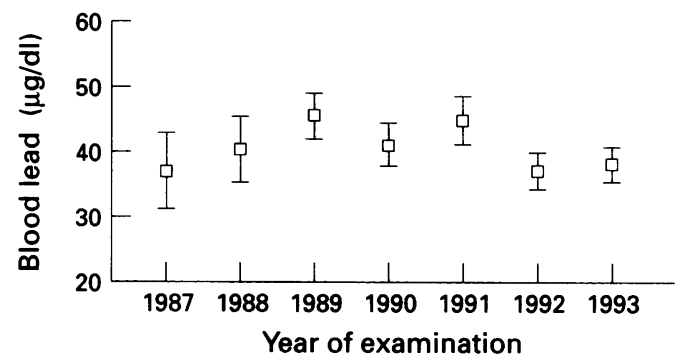

Figure 3 Mean (95\% CI) concentration of blood lead for workers with less than six years of exposure.

Figure 2 shows the mean (95\% confidence interval $(95 \% \mathrm{CI})$ ) blood lead concentration by year of examination from 1983 until 1993 (the year of the postural sway assessment) for exposed workers with more than six years of exposure. Although data were available from 1979 to 1982 , these only apply to a few workers $(<10)$ and thus were not represented in the figure. Since 1983, the mean BPbs for the factory have been declining; with a plateau from 1985 to 1988 . However, there was an increase in the mean $\mathrm{BPb}$ from 1989 until 1991, declining in 1992 and 1993 (year of the postural stability assessment). There was a gradual increase in the mean $\mathrm{BPb}$ of the workers with $\leqslant$ six years of exposure from 1987 to 1989 (fig 3). The mean $\mathrm{BPb}$ was fairly constant from 1989 to 1991 , with a decline again from 1992 to 1993.

\section{Discussion}

To our knowledge, our earlier study is the only report of postural instability among a group of workers exposed to lead compared with nonexposed workers. In that study, we were unable to establish a significant relation between present blood lead concentrations and postural sway parameters. Present blood lead concentrations of the exposed workers were primarily a reflection of exposure received in the most recent few months (not past exposure), especially in currently exposed workers. ${ }^{8}$ The action of lead on the nervous system would require time to exert and manifest its effects. In this paper, we showed that there was a significant association between most of the postural sway parameters and the cumulative blood lead in the previous two years from the date of the postural assessment (tables 4 and 5). Present blood lead concentrations were poorly correlated with most of 
the postural sway parameters (table 4). Given the present blood lead concentrations, it would be unrealistic to expect an acute effect of lead on the nervous system and thus an effect on postural stability. Therefore, the poor correlation of present concentrations of blood lead with postural sway parameters is understandable.

It was expected that the index of cumulative blood lead would be associated with the postural sway parameters. This was not our finding. The lack of relations between the index of cumulative blood lead and various postural sway parameters could be due to our present method of measurement of the index which may result in an underestimation of the worker's actual cumulative blood lead. We have adopted a pre-employment blood lead of $6.3 \mu \mathrm{g} / \mathrm{dl}$ for the 10 workers who do not have a baseline value. As such, their index of cumulative blood lead would be extrapolated based on $6.3 \mu \mathrm{g} / \mathrm{dl}$. The workers' baseline blood lead may be higher than $6.3 \mu \mathrm{g} / \mathrm{dl}$, especially in the early 1980s. Phoon and Ong ${ }^{9}$ reported mean blood lead concentrations of $16.4 \mu \mathrm{g} / \mathrm{dl}$ among sedentary workers with no known direct exposure to lead. If $6.3 \mu \mathrm{g} / \mathrm{dl}$ is an underestimation of the workers' baseline lead, the underestimation would increase with an increasing time interval between date of joining and date of first lead measurement. However, as pointed by Phoon and Ong: "... observations mentioned in this paper are not representative of all worksites in Singapore." ${ }^{9}$ In the absence of the general population data on baseline lead, we thought it would be more appropriate to base our extrapolation on the concentrations of blood lead in controls.

On the other hand, the lack of relations between index of cumulative blood lead and various postural sway parameters suggests that the effects of lead on postural stability may be reversible and therefore not associated with the index of total cumulative blood. As shown in the results, the Pearson's correlation coefficients for $\mathrm{CPbY} 2$ with $\mathrm{Vel}, \mathrm{L}, \mathrm{A}_{0}$, and $\mathrm{A}_{e}$ range from 0.34 to 0.41 when all the workers were considered (table 4). However, the correlation coefficients for CPbY2 with Vel, $L, A_{o}$ and $A_{e}$ (table 5) all showed increases (ranges from 0.49 to 0.63 with accompanying increase in significance in spite of the smaller sample size) when all the workers with more than six years of exposure were removed from the analysis.

Linz et $a l^{\beta}$ reported an improvement in postural sway test performance after $\mathrm{Ca}^{++}$EDTA chelation in an adult worker with persistent central nervous system symptoms two years after an episode of subacute lead intoxication. The patient was a 37 year old construction carpenter who two years previously, before being seen by the authors, had been working for several months cutting steel to dismantle a bridge. His blood lead concentrations went from a baseline of $15 \mu \mathrm{g} / \mathrm{dl}$ to $109 \mu \mathrm{g} / \mathrm{dl}$ and he was removed from the job. A platform posturography was performed on the worker with a computerised force platform. Three trial mean scores and the composite score were below the normal range for three of six subtests evaluating sensory organisation. The worker was chelated with intravenous $\mathrm{Ca}^{++}$EDTA for five consecutive days. Five days after the infusion, the platform posturography showed improved sensory organisation over prechelation findings. Only one of six subtests of sensory organisation was marginally abnormal. Although none of our workers exposed to lead were chelated, there were periods in their employment history, especially from 1992 onwards (figs 2 and 3), when their exposures to lead were lower. This may have provided the opportunity for recovery.

The cumulative blood lead for the past two years before the postural sway assessment, $\mathrm{CPbY} 2$, was significantly correlated with all the postural sway parameters. This suggests that an increase in postural instability may be related to an earlier increase in the blood lead concentration. From 1988 until 1991, the mean blood lead concentrations of the workers were above $40 \mu \mathrm{g} / \mathrm{dl}$. It was only from 1991, two years from the date of the postural test, that the mean blood lead concentrations had declined (fig 3). Could the higher blood lead then have affected the nervous system resulting in some postural instability?

The posture of a person depends on the degree and distribution of muscle tone and, therefore, on the activity of the motor neurons that supply the muscles. The motor neurons in the anterior grey columns of the spinal cord are the convergence points for the nervous impulses from many posterior nerve roots and the descending fibres from many different levels of the brain and spinal cord. ${ }^{10}$ Postural stability is affected by sensory information from the vestibular, proprioceptive, and visual system with the cerebellum as the centre that controls the information. ${ }^{1112}$

Nerve dysfunction involving mainly peripheral nerves has been reported to occur with blood lead as low as $40 \mu \mathrm{g} / \mathrm{dl} .{ }^{13}{ }^{14}$ Jeyaratnam $e t$ $a l$, in a study of 46 workers exposed to lead, reported significantly prolonged somatosenosory evoked potentials of the posterior tibial nerves among exposed workers with a mean blood lead concentration of $48.7 \mu \mathrm{g} / \mathrm{dl} .{ }^{15}$ The somatosensory evoked potential assesses the whole sensory neural axis inclusive of the proximal parts of the peripheral sensory nervous system (root and plexus). The somatosensory system continually provides the central nervous system with information about the position and rate of change in position of the body and its parts. The spinal cord, brain stem reticular formation, and cerebellum all use this afferent information to constantly readjust muscle tone. ${ }^{16}$ Lead may have affected the somatosensory system of the exposed workers resulting in the poorer postural stability compared with the controls.

Bhattacharya et al have reported postural instability among children who were exposed to lead. ${ }^{12}$ In a cohort of 33 children (mean blood lead of $23.5 \mu \mathrm{g} / \mathrm{dl}$ ), Bhattacharya et al ${ }^{1}$ reported that the maximum blood lead incurred during the second year of life was significantly positively related to postural sway (area of sway). In a later study, involving 63 
children, the results showed a significant relation between postnatal blood lead concentration and postural balance. ${ }^{2}$ However, in both the studies the mechanism of the postural instability among the children was not discussed.

In summary, the study showed that workers exposed to lead had significantly poorer postural stability than a control group. Lead may affect certain parts of the somatosensory system resulting in postural instability when the visual input is cut off. The cumulative blood lead for the two years before the postural sway assessment, CPbY2, was significantly positively correlated with most of the postural sway parameters. Effects of lead on postural stability may be related to recent increases in concentrations of blood lead among the exposed workers rather than cumulative body burden.

This study was carried out with Research Grant RP900339 from the National University of Singapore.

1 Bhattacharya A, Shukla R, Bornshein R. Postural disequilibrium quantification in children with chronic lead expolibrium quantification in children with chronic lead

2 Bhattacharya A, Shukla R, Bornshein RL. Lead effects on postural balance of children. Environ Helath Perspect 1990;89:35-42.
3 Linz DH, Barret ET, Pflauumer JE, Keith RE. Neuropsychlologic and postural sway improvement after Neuropsychlologic and postural sway improvement after Ca++ EDTA chelation for
Occup Med 1992;34:638-41.

4 Chia SE, Chua LH, Ng TP, Foo SC, Jeyaratnam J. Postural stability of workers exposed to lead. Occup Environ Med 1994;51;768-71.

5 Hytonen M, Pyykko I, Aalto H, Starck J. Postural control and age. Acta Otolaryngol (Stockh) 1993;113:119-22.

6 Kanter RM, Rubin AM, Armstrong CW, Cummings V. Stabilometry in balance assessment of dizzy and normal subjects. Am f Otolaryngol 1991;12:196-204.

7 Begbie GH. The effects of alcohol and varying amounts of visual information on a balancing test. Ergonomics 1966; 9:325-33.

8 Landrigan PJ, Todd AC. Direct measurement of lead in bone: a promising biomarker. $\mathscr{f} A M A$ 1994;271:239-40.

9 Phoon WO, Ong CN. Lead exposure patterns and parameters for monitoring lead absorption among workers in Singapore. Ann Acad Med Singapore 1982;11:593-600.

10 Snell RS. Dermatomes and muscular activity. In: Snell RS, ed. Clinical neuroanatomy for medical

11 Ledin T, Odkvist LM, Moller C. Posturography findings in workers exposed to industrial solvents. Acta Otolaryngologica 1989;107:357-61.

12 Bronstein AM, Hood JD, Gresty MA. Visual control of balance in cerebellar and parkinsonian syndromes. Brain 1990;113:769-79.

13 Seppalainen AM, Hernberg S, Vesanto R, Knock B. Early neurotoxic effects of lead exposure: a prospective study. Neurotoxicology 1983;4:181-92.

14 EPA. Air qualilty of criteria for lead, vols I-IV. Washington, DC: US Environmental Protection Agency, 1986. (EPA600/8-83/02aF.)

15 Jeyaratnam J, Devathasan G, Ong CN, Phoon WO, Wong PK. Neurophysiological studies on workers exposed to lead. Br F Ind Med 1985;42:173-7.

16 Burt AM. Spinal cord and brain stem control of motor function. In: Textbook of neuroanatomy. 1st ed. Philadelphia: WB Saunders, 1993:303-21. 